\title{
Sea-Blue Histiocyte Syndrome
}

National Cancer Institute

\section{Source}

National Cancer Institute. Sea-Blue Histiocyte Syndrome. NCI Thesaurus. Code C85062.

A rare, inherited or acquired syndrome characterized by the presence of histiocytes in the bone marrow which contain granules stained blue with hematoxylin-eosin stain, mild thrombocytopenia and purpura, and splenomegaly. 